\title{
HR Predictive Data Analytics in the Era of Big Data
}

\author{
Jia Yuan ${ }^{1,2}$ \\ ${ }^{1}$ Chengdu Institute of Public Administration, Chengdu, People's Republic of China \\ ${ }^{2}$ Eastern Illinois University, Charleston, IL, United States
}

Keywords: Big data, Predictive analytics, Human resource management.

\begin{abstract}
This document explains and demonstrates the application of big data in human resources management. Predictive analytics are a trend in human resources management. In this paper, we explain the concept of HR predictive analytics, and then we introduce some organizations which apply HR predictive analytics to their employees. We also do some predictive analytics research in some companies, which is very useful for human resources management and organization development. Although big data provides new methods for human resource managers, there are still some disadvantages. HR management faces a lot of challenges.
\end{abstract}

\section{Introduction}

Since the day of birth, humans have been creating stable data streams. It can be said that data exist in all aspects of our work and life. Especially in recent years, all walks of life are focused on massive data mining and applications, revealing that the era of big data has arrived. This trend has been integrated enter every job in business management, including human resource management. Human resource management in the era of big data, HR are not only relying on big data, but also learning to use big data.

Many HR technology vendors have introduced predictive analytics tools, and companies can use predictive analytics tools to analyze data on recruitment, performance, turnover, and other factors. In the next few years, data sources will continue to increase, and the prediction of employee behavior will require the integration of internal and external data. The analysis of leading companies will present more obvious cross-domain characteristics, and organizational network analysis will also become an integral part of the analysis. Online social networks within the organization will increase the size of employee social groups as they reduce lots of the friction and cost involved in contacting with others [1]. Network resources create obligations to maintain the relationship with other members of the social group, which have been found to have a positive influence on employee career success and individual performance [2].

Predictive analysis is the trend of rapid development of human resources management. Although many people are talking about predictive analysis of the human resources department, seldom organizations apply it in real practice. Burt [3] finds that the network relationships managers cultivated with those outside of their work team could foster promotion opportunities, and he also finds that managers with networks rich in structural holes could be promoted faster and at a younger age than their peers. On the other hand, one's position in the communication network predicts employee withdrawal and intentions to leave [4]. In this article, we will explain what HR prediction analysis is and how it brings changers to human resources department.

\section{The application of big data in HR predictive analytics}

\subsection{HR predictive analytics}

Currently, how does predictive analysis apply to human resources management? Human resources departments have a lot of people data. HR departments can become dependent on data-driven predictive models rather than relying on intuition by applying data predictive analysis. It enables HR to predict the impact of people policies. For example, it can prevent employee turnover. Employee 
turnover is the main cost of organization, and forecasting turnover is very important in many organizations.

Organizations face huge costs due to employee turnover. Some expenses are tangible, such as training costs and the time it takes when the employees become productive members. But the most important costs are intangible. When a productive employee leaves, new product ideas or customer relationships are lost. Human resources department may save a lot of costs for the company by applying predictive analytics, HR can help their managers and executives make better decisions.

\subsection{Predictive analytics in HR practice}

Many organizations still have a long way to go before they can produce predictive human analysis. Let's take a closer look at some of the early adopters, which have shown some interesting results.

\subsubsection{Google}

The Senior Vice President of Google's People Operations Laszlo Bock writes in his book Work Rules! [5] that the most important tool of Google's People Operations is statistics. Most importantly, Google estimates the possibility of people leaving. The company applies HR predictive analysis. One of Google's findings is that new salesmen, who have not been promoted within four years, are more likely to quit.

Google applies HR predictive analytics in recruitment, evaluation, employee development, and employee service. In recruitment, it establishes a capability model within the enterprise through big data, which can be used as a tool for initial screening. In evaluation, through the big data model in the assessment tool, the overall situation of personnel ability and quality is obtained. In employee development, Google formed a human analysis team "Oxygen" project consisting of data mining engineers, psychologists and MBAs. In employee service, Google uses a mathematical algorithm (talent retention algorithm) developed by itself to actively predict which employees are likely to leave. This allows managers to take actions before it is too late.

\subsubsection{Hewlett-Packard}

HP is a leading company in the field of human resource forecasting analysis. HP experienced a high level of employee turnover. High turnover often leads to high recruitment costs and lost revenue. In addition, employees who leave the corporation take their network and customers with them. This could cost the company a lot of money.

In 2011, two HP scientists combined the data from the past two years and tried to predict who would leave the organization. They produced a "Flight Risk "score to predict the likelihood of leaving employees by using predictive models. Their findings were groundbreaking. According to the data they could see why employees would leave HP. Higher pay, promotion and better performance ratings have negative correlation with flight risk. However, when someone received a promotion but not getting substantial salary improvement, this employee would be more likely to leave.

However, there are some practical and privacy problems with the Flight Risk score. This is why you could only grant access to this data to a selected group of senior managers. These managers could only see the scores of the employees under them. They also received training about the potential impact and confidentiality issues. In addition, the system informs managers of the key risk factors of employee turnover, and it helps to develop the strategy of retaining employees and reduce costs. Finally, Flight Risk scores can act as an early warning signal to help managers make better decisions. 2.2.3 Facebook pages

A study showed that it is possible to predict people's personality and future work performance based on their Facebook profile. The best predictive models for employee future work combine various predictors, such as IQ tests, structured interviews and personality tests. Looking at people' Facebook profile may be an extra tool to scan candidates.

\subsection{Further research}

We have done some research in Chengdu high-tech corporations. Our study examines the role of social networks in the employee promotion and intentions to quit. We use interview and data analysis during the research, we examine the role of social networks in the employee promotion and intentions 
to quit. The study offers alternate explanations for why people exit or get promoted through a data-driven approach, providing practical insights for managers trying to keep them to stay. It's useful for managers seeking to enhance employee career prospects and reduce turnover.

\section{The challenges}

Although the development and application of big data is good for HR, the data security situation is not optimistic. Human resources departments need to ensure the safety of employees' personal information.

With the rise of e-commerce and social networks, more and more people are leaving a lot of personal information on the Internet. Although companies can analyze employees by obtaining this information, improper use is likely to infringe the privacy of employees and cause huge losses to employees. Due to the sensitive nature of certain human analysis projects, companies may need to take more rigorous measures to keep data confidential, understand local regulations related to employee data usage, and guard against risks caused by company and employee private information disclosure.

\section{Summary}

It is too soon for HR to embrace the concept of big data. Predictive analysis helps HR to predict and optimize the impact of personnel policies on employees. In the context of the era of big data, personal career choices and planning are also closely linked with data. HR department can better understand employees' career interests and provide better help for their career planning and management by quantitative analysis of all employee information. For example, their promotion willingness, professional experience and performance. Companies can combine traditional career management with the management of big data.

\section{Acknowledgement}

This research was financially supported by the National Social Science Foundation of China (Grant No.15CGL029).

\section{References}

[1] M. H. Anderson, Social networks and the cognitive motivation to realize network opportunities: A study of managers' information gathering behaviors. Journal of Organizational Behavior, vol.29, pp. 51-78, 2008.

[2] N. Bozionelos and L. Wang, The relationship of mentoring and network resources with career success in the Chinese organizational environment, International Journal of Human Resource Management, vol.17, pp. 1531-46, 2006.

[3] R. S. Burt, Structural holes: The structural holes of competition. Cambridge, MA: Harvard University Press, 1992.

[4] F. M. Jablin, Organization entry, assimilation, and disengagement/exit. In F. M. Jablin and L. L. Putnam (Eds.), The new handbook of organizational communication: Advances in theory, research, and methods, Sage, Thousand Oaks, CA, pp. 732-818, 2001.

[5] B. Laszlo, Work Rules!: Insights from Inside Google That Will Transform How You Live and Lead. New York, NY: Hachette Book Group, 2015. 